\title{
EMPREENDEDORISMO: UMA ANÁLISE EM PRESIDENTE EPITÁCIO
}

\author{
Aline de Morais Cristo Melo ${ }^{1}$, Paulo Roberto Rosa ${ }^{2}$ \\ ${ }^{1}$ UNIESP. Curso de Administração, Presidente Prudente - SP. ${ }^{2}$ Instituto Federal de Educação, Ciência e Tecnologia de \\ São Paulo (IFSP) - Campus Presidente Epitácio. email: alinemoraiscm@hotmail.com
}

\section{RESUMO}

Nos dias atuais o empreendedorismo é estudado cada vez mais em instituições de ensino superior, artigos e entidades diversas com intuito de mostrar o perfil e características do empreendedor, sendo fundamental para o sucesso da empresa. Há diferenças entre empreendedores e empresários, o empresário limita-se a administrar com estilo conservador, já o empreendedor cria a empresa e procura renovar-se constantemente. Ser empreendedor não é fácil, são muitas as características que identificam um empreendedor, entre elas, iniciativa, buscas de oportunidades, persuasão, utilização de estratégia de influência e liderança. Para melhorar na organização do empreendedor, realizar um plano de negócios é de suma importância, desta forma apresentar a empresa para investidores, clientes, etc. seu novo negócio. Para isso, foi investigado junto a um empreendedor da cidade de Presidente Epitácio, no qual foi relatado seu cotidiano de como ser empreendedor turístico, ponto este focado por ele para abrir um novo negócio no município. Assim, espera-se contribuir para o enfoque do turismo na cidade de Presidente Epitácio e região.

Palavras-chave: Empreendedorismo. Empreendedor. Oportunidades. Estratégia. Liderança

\section{ENTREPRENEURSHIP: A ANALYSIS IN PRESIDENTE EPITÁCIO}

\begin{abstract}
Nowadays entrepreneurship is studied increasingly by institutions of higher education, various articles and entities with a view to show the profile and characteristics of the entrepreneur. Being critical to the success of the company. There are differences between entrepreneurs and businessmen, businessman merely administer conservative style, since the entrepreneur creates a business and are looking to renew itself. Being an entrepreneur is not easy, there are many characteristics that identify an entrepreneur, including, initiative, seeks opportunities, persuasion, use of influence and leadership strategy. The importance of preparing the business plan for company presentation or a new business. Therefore, it was investigated along with an entrepreneurial city Presidente Epitácio, which reported their daily how to be enterprising tourist, focused this point for him to open a new business in the municipality. Thus, it is expected to contribute to the focus of tourism in the city of Presidente Epitácio and region.
\end{abstract}

Keywords: Entrepreneurship. Entrepreneur. Opportunity. Strategy. Leadership. 


\section{INTRODUÇÃO}

É notável o aumento de novos empreendimentos, oportunidades e ideias, pois para ter uma boa empresa é preciso disposição, liderança, ter em si a autoconfiança, visão, assumir riscos e criatividade para transformar inovação em negócio, características essenciais para a empresa se desenvolver, assim gera expectativa, criatividade e desejo.

O empreendedor pode se basear em estudos e pesquisas, elaboradas de forma positiva e responsável, se orientar diante dos recursos, planejar e assim por diante, administrar e fazer crescer o empreendimento.

Muitos empresários não fazem as pesquisas importantes para a realização do empreendimento, por conta de sua experiência adquirida em antigos empregos, ou por se acharem autossuficientes para abrir uma nova empresa. Logo, ao abrir uma empresa deve-se ter certos cuidados, realizar pesquisas e buscar informações com clareza, além disso, o mais importante é buscar um diferencial para conquistar clientes.

mostrar a importância do empreendedorismo e o papel de um bom empreendedor para a empresa. Como comprobatório, propôs-se um estudo de caso sobre o empresário André Luiz Souza de
Almeida Castro, proprietário da Pousada Mãe D'água, instalada mais de dez anos em Presidente Epitácio - SP, no qual, obteve a oportunidade com o sucesso e sua procura é grande por turistas de toda região, do Estado de São Paulo e fora do estado.

Há, como apresentação, uma breve descrição do histórico da cidade de Presidente Epitácio, sua fundação, quando tornou-se Estância Turística.

Este trabalho tem como seu objetivo principal, verificar a importância do empreendedorismo como ferramenta de inovação e crescimento para desenvolver estratégias de negócios na empresa.

\section{METODOLOGIA}

A metodologia do trabalho baseou-se por meio de pesquisas bibliográficas, estudo de caso e pesquisa de campo de forma qualitativa, uma vez coletado dados do entrevistado, para compreender a maneira de iniciar um empreendimento.

\section{RESULTADO}

O presente trabalho demonstrou uma série de informações por meio de uma abordagem qualitativa para se comparar o que a literatura diz a respeito do empreendedor de sucesso, após a pesquisa de campo, por meio de perguntas aplicado ao empreendedor da cidade de Presidente 
Epitácio foi analisado que o empreendedor de sucesso sabe visualizar a oportunidade para abrir sua empresa e confia na potencialidade do seu negócio para influenciar na sociedade, de forma a aumentar o índice de emprego e lucratividade. Os empreendedores são visionários, capazes de identificarem as oportunidades e transformá-las em produtos e serviços inovadores. Analisado os dados colhidos, notou-se que é extremamente importante o empreendedor estar informado e atualizado antes, durante e após a abertura do empreendimento.

\section{DISCUSSÃO}

De acordo com o conteúdo estudado, pode-se dizer que o empreendedor possui características únicas como liderança, autoconfiança e assumir riscos calculados no seu negócio, assim foi possível mostrar a realidade de um empreendedor do Oeste Paulista, para ser analisado o cotidiano de um empreendedor, desta forma saber o quanto as oportunidades surgem e como lidar com o sucesso e buscar estratégias diante das dificuldades. Além disso, os empreendedores devem analisar e aplicar novas tendências de produtos e serviços, pois isso também determinará os profissionais no futuro.

\section{EMPREENDEDORISMO}

O empreendedorismo é um tema muito pesquisado nos últimos anos, de forma que as pessoas se interessam para abrir seu próprio negócio. De acordo com Hisrish apud Dornelas:

A palavra empreendedor (entrepreneur) tem origem francesa e quer dizer aquele que assume riscos e começa algo novo. Este termo empreendedorismo surgiu desde a Idade Média, com recursos do governo, apenas era gerenciador $\mathrm{e}$ não assumia riscos. (HISRISH apud DORNELAS, 2005, p. 29)

Um dos motivos pelo qual o empreendedorismo surgiu e cresce constantemente se deve ao aumento de desemprego na sociedade, de forma a mudar a posição do ex-funcionário sem opção de trabalho decide abrir um negócio e torna-se patrão.

Outro fator para alguém tornar-se empreendedor resulta por necessidade ou oportunidade. Quando o indivíduo precisa de um resultado rápido, normalmente não possui um plano, assim perde o controle e desiste de dar continuidade na empresa.

O empreendedor por oportunidade aproveita condições favoráveis para empreender de forma a prevalecer-se nos momentos oportunos, nicho de mercado, realiza pesquisas e elabora um plano de 
negócios. O indivíduo explora o campo a ser investido, analisa o local, verifica o produtos e serviços a serem comercializados e quem será seu cliente.

\section{EMPREENDEDOR E SUAS CARACTERÍSTICAS}

O perfil do empreendedor já é estudado há algum tempo por conta de sua importância econômica diante da sociedade, pois com o crescimento das empresas há uma maior geração de empregos e desenvolvimento social e financeiro na área inserida. É ele que cria novos projetos, inova no desempenho de produção.

Segundo Farah, Cavalcanti e Marcondes, afirmam que:

O perfil empreendedor é também muito requisitado nas empresas que enfrentam 0 desafio de serem competitivas no atual mundo globalizado. Por isso, estudos recentes têm apontado para a necessidade de tratar esse tema (empreendedorismo e as características do empreendedor) com mais profundidade. (FARAH; CAVALCANTI MARCONDES, 2008, p. 3)

$\mathrm{O}$ indivíduo com este perfil tem a capacidade de desenvolver criações de forma contínua e visionária em todos os lugares que estiver, em casa, no trabalho, até mesmo na rua. Para identificar um empreendedor, é necessário observar resultados na sua empresa, como também verificar sua influência perante a sociedade que circula.

A seguir serão destacados alguns itens mais detalhados sobre as características do empreendedor:

1. Capacidade de assumir riscos calculados

2. Aproveitar oportunidades, tendo iniciativa e força de vontade 3. Busca de informações e conhecimento do ramo empresarial

4. Planejamento e senso de organização

5. Liderança, comprometimento pessoal e otimismo

6. Persistência e espírito empreendedor

7. Autoconfiança

e independência pessoal

(DEGEN apud FARAH; CAVALCANTI \& MARCONDES, 1992, p. 6-7)

Importante enfatizar que nem todo empreendedor contém todas as características, se especializar é uma maneira de aprimorar o talento, o SEBRAE por exemplo realiza vários tipos de treinamentos e seminários voltados para empreendimento, para melhor especialização. Os empreendedores são visionários, capazes de observar oportunidades onde ninguém enxerga, sabem liderar e capazes de formarem boas equipes, são organizados ao planejar, dirigir um negócio e oferecer bons produtos e serviços. 


\section{PLANO DE NEGÓCIOS}

Plano de negócios é um documento, o qual o empreendedor pode apresentar para outras pessoas interessadas pelo seu projeto como investidores, bancos, clientes e empresários com o desejo de empreender ou até mesmo possui um empreendimento.

Antes de abrir um negócio, o ato de planejar é importante, a maneira que irá empreender, porque a empresa que inicia com desordem mostra a falta de organização, o empreendedor deve sempre ter a ordem para alcançar as metas e planejar fatores financeiros, estratégicos, entre outros.

Chiavenato e Sapiro comparam o plano com as guerras da antiguidade:

A guerra foi o cenário em que nasceu o conceito de estratégia, como é usualmente entendido. As constantes lutas e batalhas ao longo dos séculos fizeram com que os militares começassem a pensar antes de agir. A condução das guerras passou a ser planejada com antecipação. (CHIAVENATO \& SAPIRO, 2003, p. 27-28)

As estratégias eram planejadas antes de reagirem. Nos negócios a operação estratégica é similar, o empreendedor deve planejar antes de executar a tarefa. Para ser competitivo nos negócios é necessário planejar, isso é traçar um novo projeto, a fim de tornar sucesso e saber confrontar com diferentes desafios e utilizar todas as formas para se comunicar com clientes.

Dornelas diz:

“[...] o plano de negócios é uma ferramenta a ser aplicada tanto no lançamento de novos empreendimentos quanto no planejamento de empresas maduras". (DORNELAS, 2005, p. 97)

Vale salientar que plano de negócios mostra um empreendedor focado, e deve estar atento com inovações e tecnologias constantes do cotidiano e estar adepto a mudanças que surgir.

\section{HISTÓRICO DE PRESIDENTE EPITÁCIO}

Fundada em 1 을 de janeiro de 1907, a cidade de Presidente Epitácio - SP, no início do século $X X$, teve como primeiro comércio o de gado entre os estados de Mato Grosso e São Paulo, daí se observou a necessidade de construir a Estrada Boiadeira e a ponte que ligou os estados.

$\mathrm{Na}$ época a cidade não recebia muita atenção, não por motivos econômicos. Como apontado por Moroni:

O descaso que as sedes tinham para com Presidente Epitácio não se devia a fatores econômicos, porque em Epitácio havia grande movimento comercial, mas sim o fato de que não era visto com bons olhos o crescimento. O descontentamento pela situação de verdadeiro abandono passou para a 
etapa de indignação. A insatisfação cresceu ainda mais com a chegada de novas famílias ao distrito, que sentiam a necessidade de mudanças. (MORONI, 2008, p. 121)

Outros fatores históricos surgiram e com isso houve o aumento da população da cidade, como as imigrações húngara em 1920, japonesa nos anos 40 e a vinda de Paraguaios entre 1920 e 1970, essas imigrações influenciaram no crescimento da cidade, De acordo estimativas do IBGE, Presidente Epitácio conta com 43.155 habitantes.

Por muitos anos a economia da cidade de Presidente Epitácio - SP é gerada pelo comércio local, a variedade de empresas com diversos tipos de produtos e serviços é grande para atender os clientes.

Mas como a cidade tem o título de Estância Turística desde 20 de julho de 1990, algumas atrações são oferecidas, festivais e outros eventos ocorrentes durante o ano, principalmente em fevereiro no carnaval que há o aumento de turistas. Sempre foi bem evidenciado, o carnaval de rua com a participação das escolas de samba e animação de bandas para animar crianças e adultos.

Outra atração chamativa na cidade e região é a riqueza natural pertencente, o Rio Paraná, o qual diversas pessoas fazem questão de visitar. Com este belo cartão de visita, muitos empreendedores observaram como vantagem competitiva abrir hotéis e pousadas para melhor atender turistas que marcam presença.

\section{O CASO POUSADA MÃE D’ÁGUA}

Durante todo ano, a cidade de Presidente Epitácio - SP recebe muitos turistas, para conhecer os pontos turísticos e grande parte se hospeda em pousadas situadas na própria cidade. São mais de 30 pousadas e hotéis na cidade, empreendedores que visaram a oportunidade de negócio, dentre essas pousadas, foi-se pesquisado o empreendimento de André Luiz Souza de Almeida Castro, proprietário da Pousada Mãe D’água, localizada na direção da Estrada Vicinal sentido Campinal. Diferente de algumas pousadas, essa é uma propriedade com $11.000 \mathrm{~m}^{2}$ e tem a função de ofertar para o turista diversão e muitos outros atrativos.

Como empreendedor ele é atento, tem seus planos e estratégias, cuida de todos os detalhes, como compra de mercadorias, contabilidade, organização, funcionários. André tem todo o cuidado, conhece seus clientes, atencioso e dedicado, não fica apenas no escritório, ele é participativo e se comunica com todos, ao contrário de empreendedores, que deixam de ter contato com os clientes. 
Mas como muitos, as dificuldades iniciais ocorreram, como não tinha muito dinheiro, André obteve a ajuda do pai e da família para realizar o Marketing da pousada, desde a escolha do nome Pousada Mãe D'água, até na divulgação. Durante as férias o pai dele viajou por várias cidades, para divulgar e chamar os primeiros clientes. Em Presidente Epitácio - SP, André procurava ônibus de excursões, oferecia jantares, tudo para as pessoas conhecerem seu espaço, pode se dizer que a primeira divulgação utilizada foi o boca a boca entre as pessoas, hoje utiliza folders, rádio, televisão, redes sociais, revistas, imagens em telões na região.

Entre pescadores e família, a pousada não fica um dia sem hospede, muitos são os clientes que ao conhecer a pousada, frequentam em diversas épocas do ano, para descansar e aproveitar os atrativos, como piscina aquecida, academia, piscina com bar molhado, sauna, paint ball, escalada, internet sem fio, Espaço Kids, variado cardápio, até mesmo o Rio Paraná, uma atração natural, entre outros que proporcionam dias de lazer. Por seis anos, consecutivos recebeu premiações como a melhor pousada de Presidente Epitácio por pesquisas realizadas por empresas da região.

\section{CONCLUSÃO}

O empreendedorismo é sem dúvida um assunto com muito conteúdo a ser estudado, o qual não se pretendeu aqui esgotar. Foi possível demonstrar a capacidade do empreendedor em criar e visualizar oportunidades, ter autoconfiança, ser um bom líder, capaz de formar ótimas equipes na empresa.

Constatou-se que o sucesso do novo empreendedor é alcançado através de um plano de negócios bem estruturado. Todo empreendedor deve pesquisar, planejar e analisar o campo que será implantado na empresa. Por mais que apareçam riscos e dificuldades, o bom empreendedor é aquele que conhece seu potencial, observou em seu plano os pontos fortes e fracos, as oportunidades e ameaças, realizou análises financeiras, da concorrência, dos clientes, confeccionou planos de marketing, entre outros.

Analisou-se que a melhor forma de empreender é por oportunidade, pois o um bom empreendedor visionário está atento às informações e aproveita as melhores ocasiões para construir novos produtos e serviços. O sucesso ou fracasso de uma empresa está diretamente ligado à capacidade de conhecer o mercado em que atua e sua estrutura.

Quanto ao estudo da cidade de Presidente Epitácio/SP e do empreendedor, 
foi possível ressaltar a perspectiva de melhoria e incentivo quanto ao turismo, foco na economia e nas dificuldades expostas. Diante disso, também foi possível analisar o empreendedor que não desanima, mas sim pesquisa e explora conhecimentos, a fim de evitar problemas futuros e busca novas maneiras de incentivo ao turismo, ponto forte da cidade que ainda pode-se melhorar. Aliado ao empreendedorismo destaca-se a intuição, as experiências e a paixão do proprietário por sua empresa e pelo que faz, estes elementos também fazem a diferença para sucesso da empresa.

O objetivo proposto foi atingido por meio da pesquisa e a hipótese confirmada à medida que o empreendedorismo, na Pousada Mãe D'água, orienta e guia o proprietário empreendedor na tomada de decisões, promovendo maiores oportunidades e crescimento.

Conclui-se, portanto, que através do espírito empreendedor que possui características como perseverança, tenacidade, liderança e visão de futuro, a empresa utiliza o empreendedorismo como estratégia de negócios à medida que define metas e assume riscos calculados para alcançar seus objetivos. ng $=\&$ codmun $=354130>$. Acesso em: 01 out. 2013.

CHIAVENATO, I.; SAPIRO, A. Planejamento Estratégico: fundamentos e aplicações. 3a ed. Rio de Janeiro: Campus, 2003.

Idalberto.

Empreendedorismo: dando asas ao espírito empreendedor. 1a ed. Rio de Janeiro: Elsevier, 2005.

DORNELAS, J. C. A. Empreendedorismo: transformando ideias em negócios. 2a ed. Rio de Janeiro: Campus, 2005.

DORNELAS, J. C. A. Empreendedorismo na Prática: mitos e verdades do empreendedor de sucesso. Rio de Janeiro: Elsevier, 2007.

FARAH, O. E.; CAVALCANTI, M.; MARCONDES, L. P., Empreendedorismo Estratégico: criação e gestão de pequenas empresas. São Paulo: Cengage Learning, 2008.

MORONI, B. de G. Presidente Epitácio 100 anos da fundação da cidade. $1^{a}$ ed. Presidente Epitácio: Gráfica Epitaciana, 2008.

Recebido para publicação em 10/08/2014 Revisado em 26/08/2014 Aceito em 01/09/2014

\section{REFERÊNCIAS}

BRASIL. IBGE. Disponível em < http://cidades.ibge.gov.br/xtras/perfil.php?la 